\title{
PROGRESSIVE COLLAPSE ANALYSIS OF REINFORCED CONCRETE FRAMED STRUCTURE
}

\author{
Rakshith K G' ${ }^{1}$, Radhakrishna ${ }^{2}$ \\ ${ }^{1} P G$ student, ${ }^{2}$ Associate Dean, Department of Civil Engineering, RV college of Engineering, Bangalore-560059 \\ raks23.kg@gmail.com.
}

\begin{abstract}
The progressive collapse of reinforced concrete structures is initiated when one or more vertical load carrying members are removed due to man-made or natural hazards. The building's weight transfers to neighboring columns in the structure, leads to the failure of adjoining members and finally to the failure of partial or whole structure system. In which the collapsing system continually seeks alternative load paths in order to survive. In the present study the demand capacity ratio $(D C R)$ of reinforced concrete twelve storey framed structure are evaluated as per U.S. General Services Administration (GSA) guidelines. The Linear static analysis is carried out using software, ETABS V9.7. The structural behavior of the building for progressive collapse, a finite element model is considered using the preprocessing function of structural analysis program. Further loading are assigned to model according to IS codes. Analysis is carried out for member forces and reinforcement details. The obtained DCR values show that columns are safe and beams to be reinforced additionally.
\end{abstract}

Key words: Progressive collapse, ETABS, Finite element model, Column removal.

\section{INTRODUCTION}

The robustness of a structure is the ability of the structure to withstand local damage that may arise by accidental actions without disproportional failure that is disproportionate to the triggering cause. Progressive collapse is such a disproportional failure, which refers to the condition when the failure of a local component (or localized region) leads to global system failure. [1] The terminology of progressive collapse is defined as "the spread of an initial local failure from element to element, eventually resulting in the collapse of an entire structure or a disproportionately large part of it" [2]. After the event of 11 September 2001, more and more researchers have started to refocus on the causes of progressive collapse in building structures, seeking ultimately the establishment of rational methods for the assessment and enhancement of structural robustness under extreme accidental events. [3] Progressive collapse of a structure takes place when the structure has its loading pattern or boundary conditions changed such that structural elements are loaded beyond their ultimate capacities and fail. When any element fails, the remaining elements of the structure seek alternative load paths to redistribute the load applied to it. As a result, other elements may fail, causing failure mechanism. It is a dynamic process, usually accompanied by large deformations, in which the collapsing system continually seeks alternative load paths in order to survive. [4 and 5] One of the important characteristics of progressive collapse is that the final damage is not proportional to the initial damage.

\section{GUIDELINES PROVIDED BY THE U.S.}

\section{GENERAL SERVICES ADMINISTRATION (GSA)}

The purpose of these Guidelines is to [6]:

- Assist in the reduction of the potential for progressive collapse in new Buildings

- Assist in the assessment of the potential for progressive collapse in existing Buildings

- Assist in the development of potential upgrades to facilities if required

\subsection{Linear Static Analysis}

In the linear static analysis column is removed from the location being considered and linear static analysis with the gravity load imposed on the structure has been carried out. From the analysis results demand at critical locations are obtained and from the original seismically designed section the capacity of the member is determined. [8] Check for the DCR in each structural member is carried out. If the DCR of a member exceeds the acceptance criteria, the member is considered as failed. The demand capacity ratio calculated from linear static procedure helps to determine the potential for progressive collapse of building.

\subsection{Analysis Loading}

For static analysis purposes the following vertical load shall be applied downward to the structure under investigation: Load $=2(\mathrm{DL}+0.25 \mathrm{LL})$ 
Where,

$\mathrm{DL}=$ dead load

$\mathrm{LL}=$ live load

\subsection{Acceptance Criteria}

An examination of the linear elastic analysis results shall be performed to identify the magnitudes and distribution of potential demands on both the primary and secondary structural elements for quantifying potential collapse areas. The magnitude and distribution of these demands will be indicated by Demand-Capacity Ratios (DCR) as Eqn. 1. [8]

$$
D C R=\frac{Q_{U D}}{Q_{C E}}
$$

$Q_{U D}=$ Acting force (demand) determined in component or connection/joint (moment, axial force, shear, and possible combined forces)

$Q_{C E}=$ Expected ultimate, un-factored capacity of the component and/or connection/joint (moment, axial force, shear and possible combined forces)

Using the $D C R$ criteria of the linear elastic approach, structural elements and connections that have $D C R$ values that exceed the following allowable values are considered to be severely damaged or collapsed. [8]

The allowable $D C R$ values for primary and secondary structural elements are:

- $D C R<2.0$ for typical structural configurations.

\subsection{Scope}

For the study twelve story reinforced concrete structure is considered. The progressive collapse is initiated by removing vertical load carrying members.

\section{MODELING OF BUILDING}

For the analysis, a typical frame model of plan as shown in Fig.1 and of height $37.5 \mathrm{~m}$ is modeled using ETABS v9.7 software. The ground storey height is taken as $3.4 \mathrm{~m}$ and the rest of the storey are taken to be $3.1 \mathrm{~m}$ high. The column cross section is taken as $0.60 \mathrm{~m} \times 0.30 \mathrm{~m}$. Beam size is taken as $0.3 \mathrm{~m}$ $\mathrm{x} 0.3 \mathrm{~m}$. The floor slabs are modeled as plates of $0.15 \mathrm{~m}$ thickness. Wall having $200 \mathrm{~mm}$ thickness is considered on all the beams. All the supports are modeled as fixed supports. Linear analysis is conducted on each of these models.

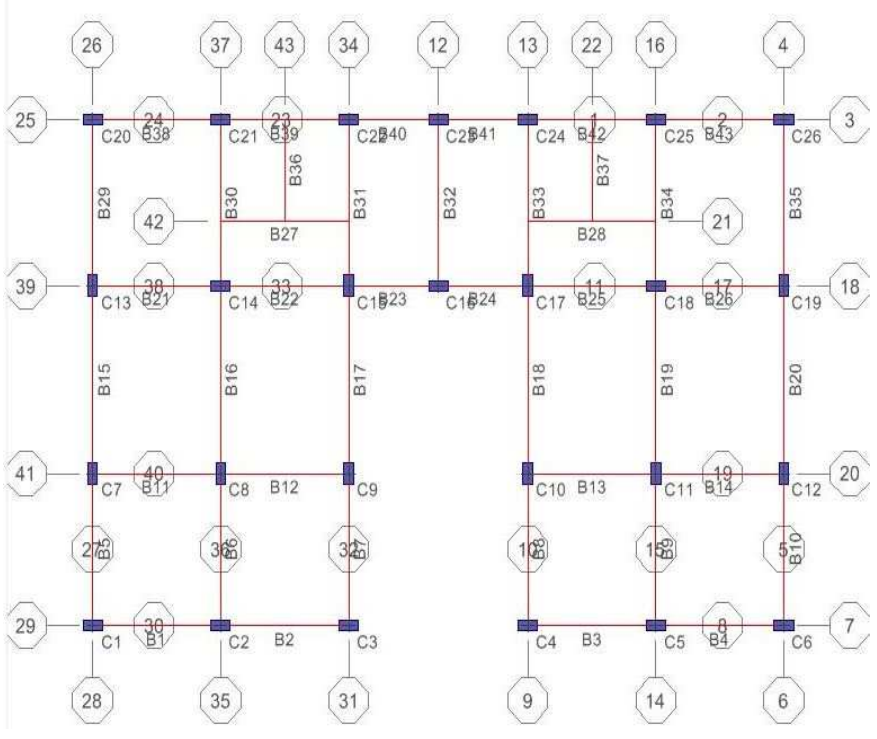

Fig.1 Plan of framed structure

Dead load [9]

Self weight of the structural elements

Floor finish $=1.5 \mathrm{kN} / \mathrm{m}^{2}$ and

Wall load on all beams is $11.16 \mathrm{kN} / \mathrm{m}^{2}$

Live load

On roof $1.5 \mathrm{kN} / \mathrm{m}^{2}$, and on floors $3.0 \mathrm{kN} / \mathrm{m}^{2}$

Seismic loading as per IS: 1893 [10]

Zone II, III, IV \&V

Soil type II, Response Reduction Factor $=3$

Importance factor $=1$

The characteristic compressive strength of concrete (fck) is 30 $\mathrm{N} / \mathrm{mm} 2$ and yield strength of reinforcing steel (fy) is 415 $\mathrm{N} / \mathrm{mm} 2$. Analysis and design of building for the loading is performed in the ETABS 9.7.Twelve storey building is designed for seismic loading in ETABS 9.7 according to the IS 456:2000.

\section{ANALYSIS}

To evaluate the potential for progressive collapse of a twelve storey symmetrical reinforced concrete building using the linear static analysis four column removal conditions is considered. First building is designed in ETABS v9.7 [11] for the IS 1893 load combinations. Then separate linear static analysis is performed for each case of column removal. Demand capacity ratio for flexure at all storeys is calculated for three cases of column failure. Column C1, C16 and C18 are removed for progressive collapse analysis in different cases. 


\subsection{Calculation of Demand Capacity Ratio:}

Capacity of the member at any section is calculated as per IS 456:2000 from the obtained reinforcement details after analysis and design. Demand capacity ratio after removal of column is found out considering the member force for the load combination as per GSA guidelines. Member forces are obtained by analysis results carried out in ETABS 9.7.

\section{RESULTS AND DISCUSSION}

The DCR values for the columns in all three cases do not exceed the acceptance criteria value suggested by GSA guidelines and hence columns are safe against progressive collapse. But for a removed column adjacent beams DCR values exceed the acceptance criteria value suggested by GSA guidelines. The DCR values of unsafe beams in all seismic zones are graphically represented.

\subsection{Graphical Representation of DCR}

After getting all the DCR values for all cases of column removal, for all zones graph is plotted DCR Vs Storeys

For column C1 removed beam B1 and B5 exceed acceptance criteria value suggested by GSA for progressive collapse guidelines as in Fig. 2 and Fig.3 respectively.

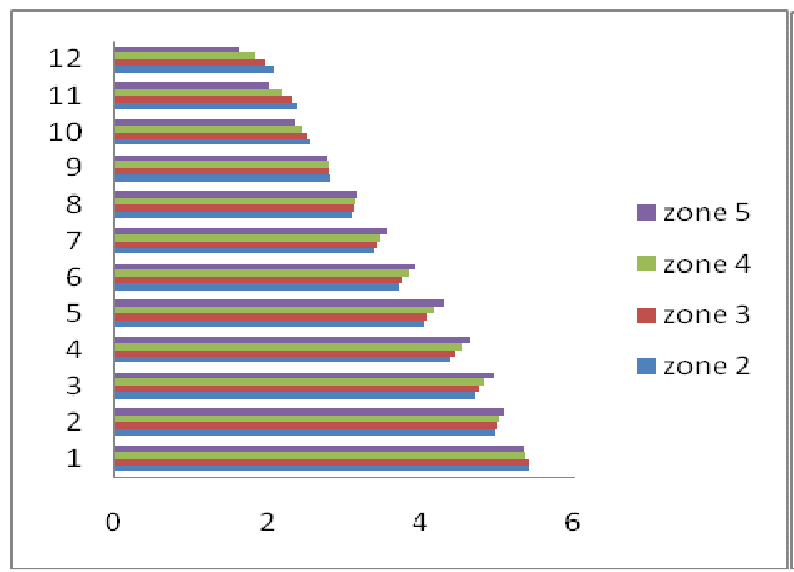

Fig.2 B1 beams DCR

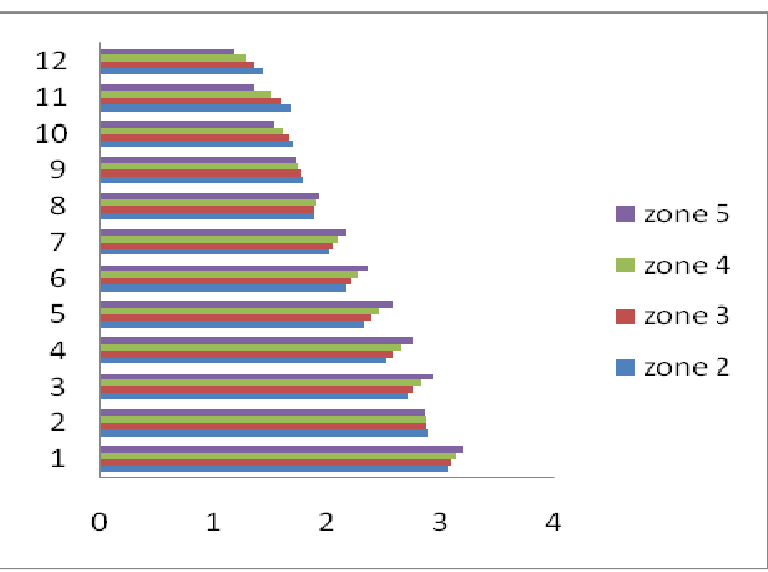

Fig.3 B5 beams DCR

For column C16 removed beam B23 and B24 exceed acceptance criteria value suggested by GSA for progressive collapse guidelines as in Fig.4 and Fig.5 respectively.

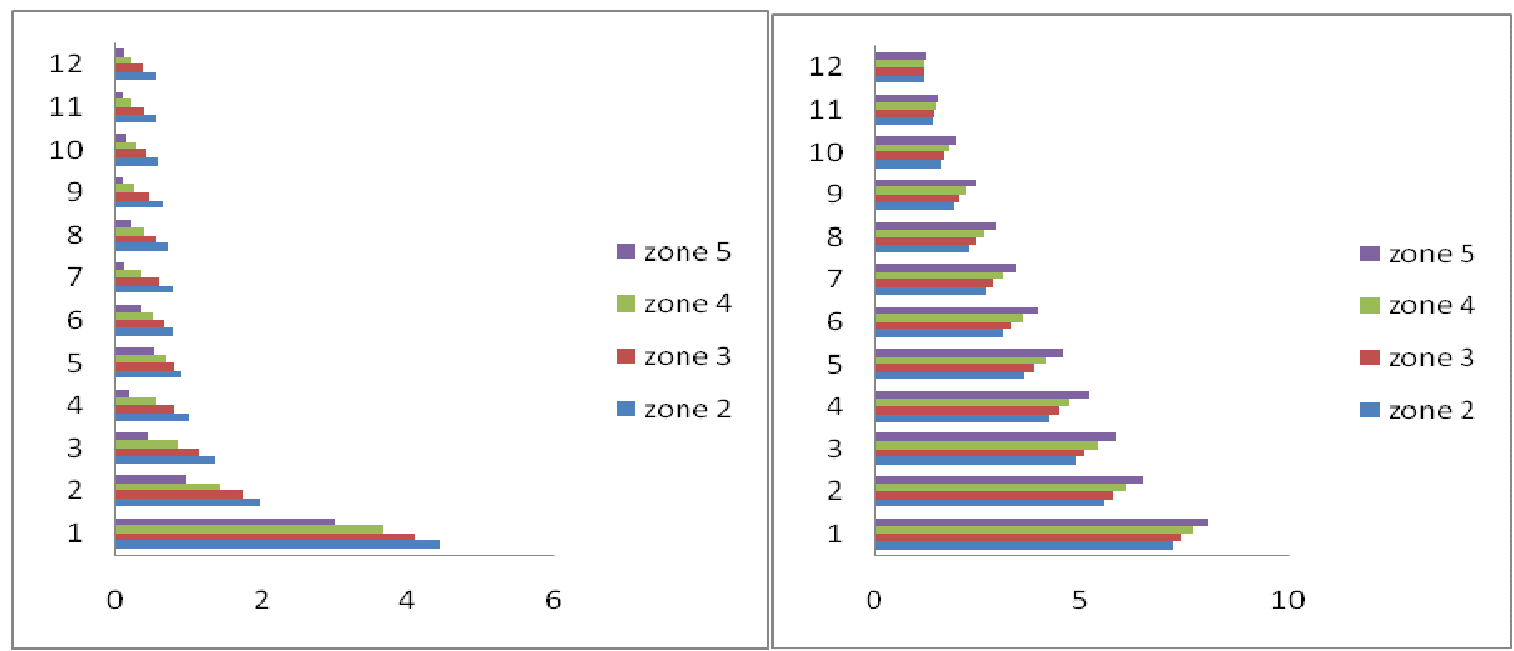

Fig.4 B23 beams DCR

Fig.5 B24 beams DCR 
For column C18 removed beam B25 and B26 exceed acceptance criteria value suggested by GSA for progressive collapse guidelines as in Fig.6 and Fig.7 respectively.

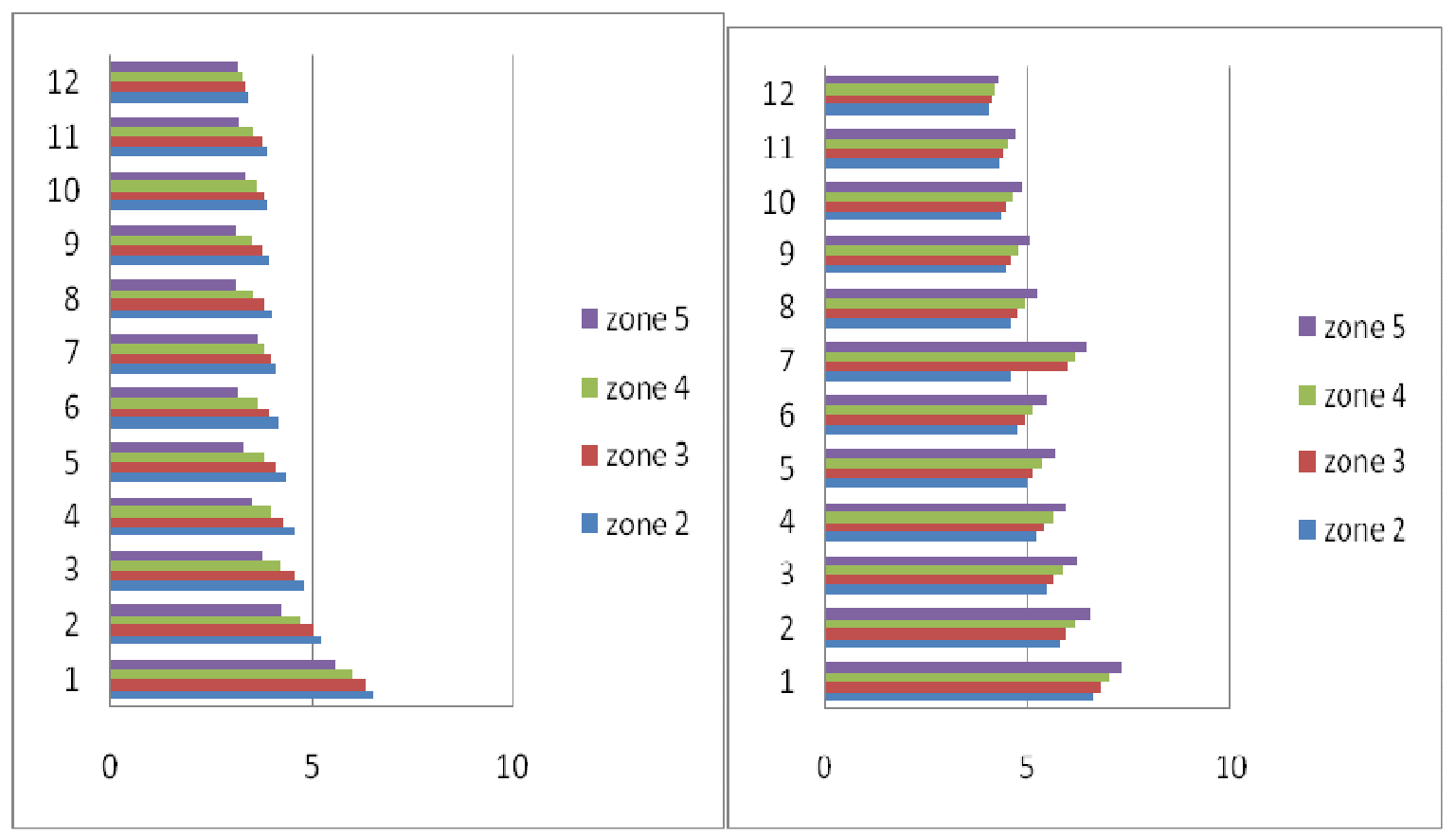

Fig.6 B25 beams DCR

Fig.7 B26 beams DCR

\section{CONCLUSIONS}

Based on the limited study of progressive collapse on reinforced framed structure the following broad conclusions can be made.

1. The DCR values of columns are less than two; it suggests that columns are safe as per GSA guidelines for progressive collapse analysis. Hence seismically designed building columns have inherent ability to resist progressive collapse.

2. The beams whose DCR values are more than acceptance criteria value suggested by GSA for progressive collapse guidelines are unsafe. That beams were found to be adjacent to the removed column in respective cases.

3. To avoid the progressive failure of beams and columns, caused by failure of particular column, adequate reinforcement is required to limit the DCR within the acceptance criteria.

The adequate reinforcement provided in extra to beams which are unsafe can develop alternative load paths and prevent progressive collapse due to the loss of an individual member.

\section{REFERENCES}

[1] Feng Fu Progressive collapse analysis of high-rise building with 3-D finite element modeling method. Journal of Constructional Steel Research 65 (2009) 1269_1278.

[2] B.A. Izzuddin, A.G. Vlassis, A.Y. Elghazouli, D.A. Nethercot - Progressive collapse of multi-storey buildings due to sudden column loss Part I: Simplified assessment framework. Engineering Structures 30 (2008) 1308-1318.

[3] Jae-hyouk Choi, Dong-kuk Chang - Prevention of progressive collapse for building structures to member disappearance by accidental actions. Journal of Loss Prevention in the Process Industries 22 (2009) 10161019.

[4] Kapil Khandelwal, Sherif El-Tawil - Pushdown resistance as a measure of robustness in progressive collapse analysis. Engineering Structures 33 (2011) 2653-2661.

[5] Hyun-Su Kim, Jinkoo Kim, Da-WoonAn Development of integrated system for progressive collapse analysis of building structures considering dynamic effects. Advances in Engineering Software 40 (2009) 1-8. 
[6] H.M. Salema, A.K. El-Fouly , H.S. Tagel-Din - Toward an economic design of reinforced concrete structures against progressive collapse Engineering Structures 33 (2011) 3341-3350.

[7] Seweryn Kokot ,ArmelleAnthoine, Paolo Negro, George Solomos - Static and dynamic analysis of a reinforced concrete flat slab frame building for progressive collapse. Engineering Structures 40 (2012) 205-217.

[8] General Services Administration (GSA). (2003). Progressive collapse analysis and design guidelines for new federal office buildings and major modernization projects, GSA.

[9] IS 456:2000 (2005). Plain and reinforced concrete code of practice, 4th Revision, 7th Reprint, Bureau of Indian Standards, New Delhi.

[10] IS 1893 (Part 1):2002 (2006). Criteria for earthquake resistant design of structures. $5^{\text {th }}$ Revision, 3rd Reprint, Bureau of Indian Standards, New Delhi.

[11] ETAB v 9.6 analysis reference manual, Computers and Structures, Inc., Berkeley.

[12] Yanchao Shi, Zhong-Xian Li, Hong Haoa, - A new method for progressive collapse analysis of RC frames under blast loading. Engineering Structures 32 (2010) 1691_1703. 